alphabetical list of members of the Executive Committee, scientific and special committees, the Council, and officers of the Scientific Unions.

\section{Polish Science Publications}

The Quarterly Review of Scientific Publications (No. 1; 1964), issued by the Polish Academy of Sciences, now covers all scientific books published in Poland. There are 439 entries arranged under headings: gencral; social sciences; biological sciences; pure and technical sciences. There is an index of authors and a subject index.

The Review of the Polish Academy of Sciences for January-March $(9$, No. 1; 1964) includes articles by S. Huechel on the development of research on soil mechanics in Poland, and by J. Dylik on peri-glacial investigations and their significance for palæogeography, as well as an account by $\mathrm{P}$. Kubchowski of the history, development and activities of the Institute of Drugs.

Polish Scientific Periodicals, which will appear ten times a year, and of which Nos. 1 and 2, 1964, have now been published, lists the contents of periodicals published in Poland, arranged under social sciences, biological sciences, pure and technical sciences, and includes an author index. The publication is available from the Polish Academy of Sciences, Palace of Culture and Sciences, Warsaw.

\section{Land Resources in Australia}

THE identification of distinctive environments and the pattern of their occurrence are the principal tasks of the Commonwealth Scientific and Industrial Research Organization Division of Land Research and Regional Survey, and the annual report for $1962-63$ presents a review of the activities in progress (Pp. 73. Canberra: Division of Land Research and Regional Survey, C.S.I.R.O., 1963). The Land Resources Group has been engaged since 1946 in reconnaissance surveys of large areas, land systems being described to provide basic data for possible land use; productive land use for specific environments is the objective of the Biology Groups; the overall appraisal of the situation with respect to possiblo commercial production is made by the Agricultural Assessment Group. There is close co-operation throughout with other divisions of the Commonwealth Scientific and Industrial Research Organization. Most of the field work has been carried out in Northern Australia and Papua-New Guinea, with research stations in Northern Territory at Katherine, for crops suitable for monsoon conditions; at Darwin, for rice with seasonal flooding; at Alice Springs, for the problems of arid country; and in Western Australia at Kimberloy, for irrigation investigations. Pasture management and the performance of tropical cross-bred cattle, peanut cultivation, selection of cotton varieties and cropping systems with oil seeds, and fluctuations in productivity resulting from erratic distribution of rainfall, are some of the problems under investigation. Water is obviously a dominant factor, and the work is supported by flexibly constituted research units concerned with plant-soil-climate relationships, investigations being directed, for example, to questions of stomatal behaviour in transpiration, transpiration suppressants, diurnal energy and water exchange, nutrient responses, and harmonic analysis of rainfall data. Environmental limitations inevitably impose restrictions on agricultural potential, and the information being collected will be invaluable.

\section{Forest Products Research}

THE Forest Products Rescarch Laboratory has compiled a list of its publications which can be obtained free of charge on application to the Laboratory. The list consists of a selection of abstracts of papers published by Labora. tory staff during the past few years together with a few Laboratory reports of which stocks of reprints are still available. Topics covered by the reports include: season- ing; woodworking; strength; protections of timber from fungal and insect attack; composite wood; chemistry; general and miscellaneous; industrial surveys. Copies of the list are available from the Director, Forest Products Research Laboratory, Princes Risborough, Aylesbury, Bucks.

\section{Wind and Locust Migration}

AN understanding of the factors which determine the course of locust migrations is becoming increasingly important, not only for the purpose of predicting which areas are likely to be invaded but also in order to make the most effective use of aircraft in the application of insecticides. Meteorology and the Migration of Desert Locusts : Applications of Synoptic Meteorology in Locust Control, by R. C. Rainey, is an exhaustive technical study of the applications of synoptic meteorology in locust control (World Meteorological Organization. Technical Note No. 54. (WMO No. 138. TP. 64. Anti-Locust Memoir 7.) Pp. v $+115+3$ plates. Geneva: World Meteorological Organization; London: Anti-Locust Research Centre, 1964. 25 Sw. fr.; 42s.). Hour-to-hour displacements of individual swarms have been recorded from the air. The direction of displacement follows closely the direction of the winds at swarm level. They may show a steady progressive displacement or there may be repeated reversals, sometimes resulting in closed loops. This down-wind displacement can lead to convergence of swarms or dispersal. A sound basis is thus provided for the use of current synoptic charts and of meso-scale metcorological observations in the interpretation and in the short-term forecasting of the movements of the desert locust.

\section{Radiation Nephritis}

Dr. John G. MAIER, of the Walter Reed Army Institute of Research, and Dr. George W. Casarett, of the University of Rochester, New York, have investigated the effects of single-exposure localized irradiation of the kidneys in beagle dogs at $500,1,000$ and 2,000 rads, using $220-\mathrm{kV}$ $\mathrm{X}$-rays (Transactions of the New York Academy of Sciences, Serial 2, 26, No. 5; March 1964). Both functional and morphological parameters have been investigated in animals killed six months after irradiation. One or both kidneys have been irradiated in situ, and single kidneys have been exteriorized and irradiated. From these and earlier experiments, it is concluded that irradiation of the canine kidney produces a progressive arteriolonephrosclerosis. The dogree and rate of progression are related to the absorbed dose. At six months following irradiation, minimal arteriolonephrosclerotic changes were seen in the dog kidney receiving 500 rads, severe changes at 2,000 rads, and intermediate changes at 1,000 rads.

\section{Harkness Fellowships of the Commonwealth Fund- New York}

Thirty Harkness fellowships of the Commonwealth Fund-New York are offered each year for study and travel in the United States. Candidates must be British subjects who are citizens of the United Kingdom and present Colonies by birth or by naturalization. Candidates should be between 21 and 32 years of age on September 1, 1965. Recent graduates and graduands who expect to receive their first degree in 1965 may apply, if they do not intend an acadomic career. Graduates proposing an academic career should have experience of postgraduato research. Othor candidates, including non-graduates, should produce evidence of professional qualifications or considerable practical experience. The fellowships are tenable for between twelve and twenty-one months. Round-trip passages to the United States are provided. Emoluments include living and family allowances, travel in the United States, tuition and research expenses, and allowances. Selection of Fellows for nomination to tho 